\title{
Aquecimento global e mudanças climáticas na visão de adultos residentes em cidades paulistas
}

RESUMO: Este trabalho, por meio de entrevistas realizadas em meados de 2009, nas cidades de São Bernardo do Campo, Santo Antonio de Posse, Pederneiras e Tapiratiba, localizadas no Estado de São Paulo, Brasil. $O$ objetivo foi avaliar se a população tinha informações a respeito do aquecimento global e mudanças climáticas. Em caso de uma resposta afirmativa, procurou-se conhecer as principais fontes de informação a que teve acesso e suas posições pessoais diante de um assunto polêmico na atualidade. Verificou-se que sobre mudanças climáticas, suas causas e conseqüências, as pessoas ainda adquirem mais informações na televisão e na internet, o que é preocupante, haja vista que os fatos divulgados pelas redes televisivas e pela rede mundial de computadores são, muitas vezes, alarmistas e desprovidos de fundamentos científicos.

\section{Aquecimento global e mudanças climáticas na visão de adultos residentes em cidades paulistas}

\author{
Antonio Carlos Tavares* \\ Solange T. de Lima-Guimarães* \\ Camila Alves de Brito** \\ Caroline Lucon Rocha** \\ Priscila \\ Andrade** \\ Ambrósio de \\ Stefânia Cristina de Oliveira** \\ * Professor Adjunto do \\ Departamento de Geografia da \\ Universidade Estadual Paulista, \\ Campus de Rio Claro. \\ ** Discentes do Curso de \\ Graduação em Geografia da \\ Universidade Estadual Paulista, \\ Campus de Rio Claro.
}

Palavras-chave: Aquecimento Global; Mudanças Climáticas; Política Estadual de Mudanças Climáticas; Mídia; Medidas Mitigadoras.

Key-words: Global Warming; Climate Changes; State Policy on Climate Changes; Media; Mitigation Measures.

\begin{abstract}
This study was conducted through interviews in mid-2009, in the cities of São Bernardo do Campo, Santo Antonio de Posse, Pederneiras and Tapiratiba, located in São Paulo State, Brazil. The aim was to evaluate if the population had information about the global warming and climate changes. In case of an affirmative answer, the main sources of information that they had access were identified and also their personal views on this controversial subject today. Regarding the climate changes and its causes and consequences, it was found that people acquire more information through television and internet, which is worrying, given that the facts disclosed by the television networks and the worldwide computers network, are often alarmist and lacking scientific foundation.
\end{abstract}




\section{Introdução e Objetivos}

De acordo com o divulgado por cientistas, principalmente por aqueles citados pelo Painel Intergovernamental de Mudanças Climáticas (IPCC), com ampla repercussão na mídia, gases oriundos de atividades antrópicas, principalmente dióxido de carbono, metano e óxido nitroso, estariam acentuando 0 efeito estufa e possibilitando o aumento global das temperaturas da Terra. Por existir na atmosfera em quantidade maior do que os outros gases apontados como intensificadores do efeito estufa, o dióxido de carbono é apontado como o principal responsável pelo aquecimento global registrado pelo planeta, de forma contínua, nas últimas quatro décadas. $\mathrm{O}$ uso de combustíveis fósseis responderia por, aproximadamente, $77 \%$ do $\mathrm{CO}_{2}$ adicionado ao ar, enquanto o restante seria proveniente dos desmatamentos e das queimadas associadas às práticas agrícolas. Este gás passou de uma concentração de 280 ppmv, em meados do século XVIII, para 379 ppmv, o que representaria um acréscimo de $35,3 \%$ nos últimos dois séculos e meio. Sua concentração na atmosfera cresceu, entre 1995 e 2005, numa taxa anual de 1,9 ppmv (IPCC, 2001, 2007). 0 aquecimento global seria responsável por mudanças climáticas, pelo derretimento das geleiras, pela elevação do nível do mar, pela disseminação de doenças e pragas e por tempestades, enchentes, secas e furacões, entre outros efeitos (IPCC, 2001, 2007).

Supondo que as previsões do IPCC estejam corretas, a adoção de medidas para enfrentar as conseqüências do aquecimento global, além da solução de problemas e conflitos socioeconômicos e das posições políticas dos diversos países, necessita, no nível local, atitudes pró-ambientais condizentes da população diante das situações a ser enfrentadas, pois, sem dúvida, os posicionamentos populares, em qualquer situação, exercem pressão sobre decisões que as esferas político-administrativas vierem a tomar. Nesse contexto, as questões e informações vinculadas a tal tema, desvinculadas de paixões e sem uma visão catastrófica eminente, como muitas vezes exposta na mídia, ou ainda a disseminação de informações equivocadas, é muito importante para a formação de opiniões e para que a população passe a acompanhar, com interesse, a divulgação de pesquisas e os debates sobre 0 assunto.

Assim, por meio de entrevistas com adultos de vinte anos ou mais, realizadas em meados de 2009 em quatro cidades paulistas, a pesquisa procurou saber se os indivíduos já tinham ouvido falar sobre 0 aquecimento global e, diante de respostas afirmativas, as questões a seguir formuladas buscaram conhecer as principais fontes de informação a que os entrevistados tiveram acesso e suas percepções e interpretações pessoais diante de um assunto polêmico.

\section{Universo da Pesquisa}

As informações foram coletadas em São Bernardo do Campo, Santo Antonio de Posse, Pederneiras e Tapiratiba, localizadas em diferentes mesorregiões do estado de São Paulo (SP). A cidade de São Bernardo do Campo está localizada na mesorregião metropolitana de São Paulo e possuía uma população estimada de 816 mil habitantes em 2009, segundo a Fundação

Geografia Ensino \& Pesquisa, v. 15, n.2, p. 75-86, maio./ago. 2011

Aquecimento global e mudanças climáticas na visão de adultos residentes em cidades paulistas ocasião, entre 13 mil e 42 mil habitantes (figura 1 e tabela 1 ). 


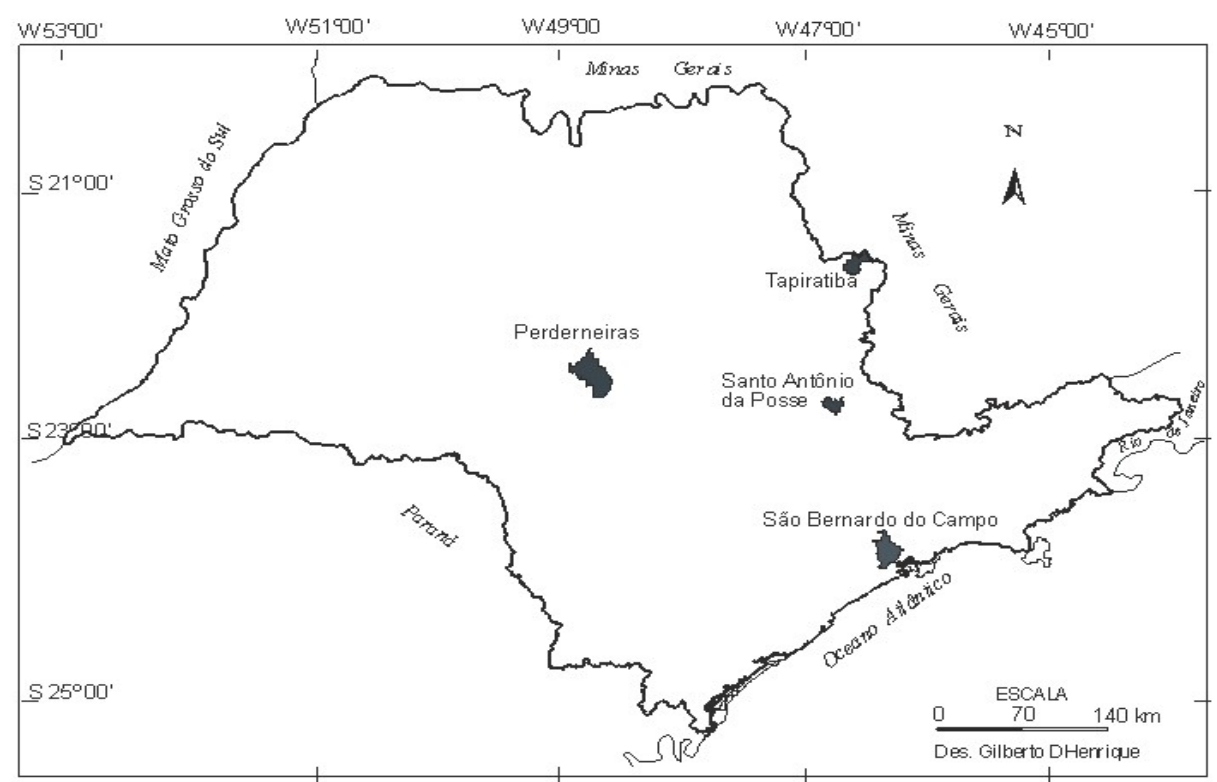

Figura 1 - Localização das cidades estudadas no estado de São Paulo.

No contexto socioeconômico, São Bernardo do Campo possui uma alta densidade populacional e uma economia baseada no comércio e na indústria, tendo em vista a ausência de área rural, o que lhe dava em 2007, um Produto Interno Bruto (PIB) per capita superior a $R$ \$ $32.000,00$ (trinta e dois mil reais). O PIB per capita nos outros três municípios oscilava, em 2009, entre $R \$ 12.500,00$ (doze mil e quinhentos reais), em Tapiratiba, $R \$ 17.144,00$, em Pederneiras, e R\$ 18.500,00 (dezoito mil e quinhentos reais), em Santo Antonio de Posse, ambos na mesorregião de Campinas. Nestes dois municípios mencionados os empregos na agricultura superavam os existentes nas atividades comerciais. Em Pederneiras, na mesorregião de Bauru, os vínculos empregatícios na agricultura e no comércio eram equivalentes e correspondiam a cerca de $50 \%$ dos existentes no setor industrial (tabela 1 ).

\begin{tabular}{|c|c|c|c|c|}
\hline \multirow[t]{2}{*}{ Atributos } & \multicolumn{4}{|c|}{ Cidades } \\
\hline & São B. do Campo & Santo A. de Posse & Tapiratiba & Pederneiras \\
\hline Latitude (S) & 23041 ' 38 "' & $22036^{\prime} 23^{\prime \prime}$ & $21028^{\prime} 40^{\prime \prime}$ & $22021^{\prime} 07^{\prime \prime}$ \\
\hline Longitude (0) & $46033^{\prime} 53^{\prime \prime}$ & $46055^{\prime} 08^{\prime \prime}$ & $46044^{\prime} 54^{\prime \prime}$ & $48046^{\prime} 30^{\prime \prime}$ \\
\hline População ${ }^{1}$ & 816.599 & 22.016 & 13.730 & 41.571 \\
\hline População (14/19)2 & 63.700 & 1.831 & 1.289 & 3.669 \\
\hline PIB $(\mathrm{R} \$)^{3}$ per capita & 32.667 & 18.557 & 12.533 & 17.114 \\
\hline Agropecuária (\%) & 0,02 & 14,99 & 34,43 & 15,05 \\
\hline Indústria $(\%)^{4}$ & 37,93 & 19,78 & 36,52 & 36,63 \\
\hline Comércio $(\%)^{4}$ & 44,12 & 12,99 & 9,63 & 16,45 \\
\hline
\end{tabular}

1 - População do município (2009), ${ }^{2}$ - População entre 14 e 19 anos (2009), ${ }^{3}$ - PIB per capita (2007), ${ }^{4}$ - Vínculos empregatícios na agropecuária, indústria e comércio (2008)

Tabela 1 - Localização e Atributos das Cidades onde foi Realizada a Pesquisa Fonte: SEADE,

Geografia Ensino \& Pesquisa, v. 15, n.2, p. $75-86$, maio./ago. 2011

Tavares, A. C. et. all

ISSN 2236- 4994 
Em Pederneiras e São Bernardo do Campo foram entrevistadas 50 pessoas, sendo 23 homens e 27 mulheres na primeira cidade mencionada, e 25 indivíduos de ambos os sexos na outra. Em Tapiratiba, foram ouvidos 25 homens e 27 mulheres, e em Santo Antonio de Posse, 23 adultos do sexo masculino e 24 do feminino. Assim, no total, 96 homens e 103 mulheres responderam as perguntas formuladas. Das 199 pessoas entrevistadas, 35,7\% tinham de $20 \mathrm{e}$ 29 anos, $21,1 \%$ de 30 e $39,20,1 \%$ de 40 e $49,15,6 \%$ de 50 a 59 e 7,5\% possuíam idade igual ou superior a 60 anos. Houve, portanto, uma distribuição equitativa em relação ao número de indivíduos existentes nas diferentes faixas etárias. 33,2\% dos entrevistados tinham o curso superior incompleto, 29,7\% o ensino médio completo e $25,1 \%$ o curso superior completo, totalizando $88 \%$ da amostra. Portanto, a escolaridade dos entrevistados era elevada em relação à população brasileira, haja vista que $58,3 \%$ estavam cursando ou haviam concluído o ensino superior. Destacaram-se, no conjunto da amostra, as pessoas que, de 20 a 29 anos, estavam cursando a universidade. Dentre os que a haviam findado $7,6 \%$ eram desta faixa etária, $6 \%$ tinham idade de 30 a 39 anos, 5,5\% de 40 a 49 anos e outros 5,5\% de 50 a 59 anos. 0 maior percentual de indivíduos com ensino médio completo, 10,7\% da amostra, estava na faixa etária de 40 a 49 anos. $6,0 \%$ de todos os entrevistados, entre 20 e 29 anos, 5,5\% entre 30 e 39 e 5,5\% de 50 a 59 anos também possuíam esse nível de ensino (tabelas 2 e 3 ).

\begin{tabular}{c|c|c|c|c|c|c|c|c|c}
\hline \multirow{2}{*}{ IDADES } & \multicolumn{2}{|c|}{ PEDERNEIRAS } & \multicolumn{2}{|c|}{ S. B. DO CAMPO } & \multicolumn{2}{|c|}{ TAPIRATIBA } & \multicolumn{2}{c}{ S. A. DE POSSE } & TOTAIS \\
\hline & $\mathrm{M}$ & $\mathrm{F}$ & $\mathrm{M}$ & $\mathrm{F}$ & $\mathrm{M}$ & $\mathrm{F}$ & $\mathrm{M}$ & $\mathrm{F}$ & \\
\hline $20-29$ & 11 & 4 & 1 & 4 & 14 & 18 & 9 & 10 & 71 \\
\hline $30-39$ & 4 & 4 & 10 & 8 & 4 & 2 & 5 & 5 & 42 \\
\hline $40-49$ & 4 & 11 & 8 & 7 & 5 & 1 & 3 & 1 & 40 \\
\hline $50-59$ & 4 & 6 & 5 & 4 & 1 & 2 & 4 & 5 & 31 \\
\hline $60 \mathrm{e}+$ & 0 & 2 & 1 & 2 & 1 & 4 & 2 & 3 & 15 \\
\hline TOTAIS & 23 & 27 & 25 & 25 & 25 & 27 & 23 & 24 & 199 \\
\hline
\end{tabular}

Tabela 2 - Distribuição dos Entrevistados por Sexo e Faixa Etária

\begin{tabular}{c|c|c|c|c|c|c}
\hline \multirow{2}{*}{ ESCOLARIDADE } & \multicolumn{7}{|c}{ IDADE } \\
\hline & $20-29$ & $30-39$ & $40-49$ & $50-59$ & 60 e & Totais \\
\hline Ausente & 0,0 & 0,0 & 0,0 & 0,0 & 0,5 & 0,5 \\
\hline Fundamental Incompleto & 0,0 & 1,0 & 1,0 & 0,5 & 2,0 & 4,5 \\
\hline Fundamental Completo & 0,0 & 0,5 & 0,5 & 1,0 & 1,5 & 3,5 \\
\hline Médio Incompleto & 1,0 & 1,0 & 0,0 & 1,0 & 0,5 & 3,5 \\
\hline Médio Completo & 6,0 & 5,5 & 10,7 & 5,5 & 2,0 & 29,7 \\
\hline Superior Incompleto & 22,1 & 7,1 & 2,0 & 2,0 & 0,0 & 33,2 \\
\hline Superior Completo & 7,6 & 6,0 & 5,5 & 5,5 & 0,5 & 25,1 \\
\hline Totais & 36,7 & 21,1 & 19,7 & 15,5 & 7,0 & 100,0 \\
\hline
\end{tabular}

Tabela 3 - Distribuição dos Entrevistados por Faixa Etária e Escolaridade em \%

Aquecimento global e mudanças climáticas na visão de adultos residentes em cidades 


\section{Levantamento dos Dados}

Cada entrevistado respondeu oito perguntas, sendo cinco delas fechadas e outras três abertas. A primeira pergunta procurou saber dos entrevistados se eles tinham conhecimento de que, para um grupo de cientistas, a Terra estava sofrendo um aquecimento e que tal fato alteraria os climas do planeta.

\begin{tabular}{c|c|c|c|c|c|c|c|c}
\hline \multirow{2}{*}{ IDADES } & \multicolumn{2}{|c|}{ PEDERNEIRAS } & \multicolumn{2}{|c|}{ S. B. DO CAMPO } & \multicolumn{2}{c|}{ TAPIRATIBA } & \multicolumn{2}{c}{ S. A. DE POSSE } \\
\hline & $\mathrm{S}$ & $\mathrm{N}$ & $\mathrm{S}$ & $\mathrm{N}$ & $\mathrm{S}$ & $\mathrm{N}$ & $\mathrm{S}$ & $\mathrm{N}$ \\
\hline $20-29$ & 15 & 0 & 5 & 0 & 32 & 0 & 19 & 0 \\
\hline $30-39$ & 8 & 0 & 17 & 1 & 6 & 0 & 10 & 0 \\
\hline $40-49$ & 15 & 0 & 15 & 0 & 6 & 0 & 4 & 0 \\
\hline $50-59$ & 10 & 0 & 9 & 0 & 3 & 0 & 9 & 0 \\
\hline 60 e + & 1 & 1 & 3 & 0 & 3 & 2 & 5 & 0 \\
\hline TOTAIS & 49 & 1 & 49 & 1 & 50 & 2 & 47 & 0 \\
\hline
\end{tabular}

Tabela 4 - Pessoas que Tinham Informações do Aquecimento

A quase totalidade das pessoas, nas quatro cidades, independentemente da faixa etária, tinha conhecimento de que, na visão de uma corrente científica, as temperaturas do planeta estão aumentando. Apenas quatro pessoas disseram desconhecer esse fato e, portanto, elas deixaram de responder as perguntas formuladas a seguir (tabela 4).

Perguntou-se aos entrevistados, em seqüência, quais as fontes que thes permitiram auferir os conhecimentos a respeito do aquecimento global. A questão elaborada de forma aberta permitiu que cada pessoa elencasse uma ou mais origens para a elaboração do seu saber sobre 0 assunto (tabela 5).

\begin{tabular}{c|c|c|c|c|c|c}
\hline \multirow{2}{*}{ FONTES } & \multicolumn{7}{|c}{ IDADE } \\
\hline & $20-29$ & $30-39$ & $40-49$ & $50-59$ & 60 e & Totais \\
\hline Escola & 7,4 & 2,3 & 0,0 & 1,4 & 0,0 & 11,1 \\
\hline Rádio & 0,3 & 0,6 & 2,8 & 2,3 & 0,3 & 6,3 \\
\hline Televisão & 14,3 & 10,2 & 11,6 & 5,9 & 3,1 & 45,1 \\
\hline Jornal & 3,7 & 2,3 & 3,1 & 3,1 & 1,7 & 13,9 \\
\hline Livro & 0,0 & 0,3 & 1,4 & 0,0 & 0,0 & 1,7 \\
\hline Internet & 7,1 & 3,7 & 2,0 & 2,0 & 0,0 & 14,8 \\
\hline Palestra & 0,6 & 2,5 & 0,6 & 0,3 & 0,0 & 4,0 \\
\hline Amigos & 1,4 & 0,8 & 0,3 & 0,0 & 0,0 & 2,5 \\
\hline Outras & 0,6 & 0,0 & 0,0 & 0,0 & 0,0 & 0,6 \\
\hline Total & 35,4 & 22,7 & 21,8 & 15,0 & 5,1 & 100,0 \\
\hline
\end{tabular}

Tabela 5 - Fontes das Informações Sobre o Aquecimento Global em \% por Faixa Etária

Geografia Ensino \& Pesquisa, v. 15, n.2, p. 75-86, maio./ago. 2011

Tavares, A. C. et. all 
A televisão foi a principal fonte de informação mencionada por pessoas de todas as faixas etárias, abarcando $45,1 \%$ das respostas. Para os mais jovens, que na maioria ainda estão cursando o nível superior, a escola surgiu em segundo lugar, com 7,4\% de todas as citações, e a internet em terceiro, com 7,1\%. Na faixa etária de 20 a 29 anos, a soma dessas duas fontes igualou a influência da televisão. Entre as pessoas com 30 a 39 anos a internet figurou como a segunda fonte de informação, com $3,7 \%$ das menções totais, seguida de perto pela influência similar de palestras, jornais e da escola. Para os adultos dessa idade todas essas fontes, somadas, exerceram papel similar ao da televisão, que foi lembrada em $10,2 \%$ das respostas. Para a faixa etária de 50 a 59 anos o jornal, o rádio e a internet juntos superaram a influência da televisão e para os mais idosos a televisão e os jornais constituíram praticamente as únicas fontes de informação (tabela 5).

Foi indagado se as pessoas acreditavam que, diante das informações obtidas, a Terra estava sofrendo um processo de aquecimento. As respostas para essa pergunta estão expostas na tabela 6. Das 195 pessoas que se disseram informadas sobre o assunto, 29 delas ou 14,9\% disseram não acreditar que a Terra esteja passando por mudanças climáticas em decorrência do aumento das temperaturas. Os descrentes se distribuem por todas as faixas etárias e a maior parte deles está na cidade de Pederneiras, abrangendo $24,5 \%$ das pessoas que responderam a essa questão naquela cidade. São Bernardo do Campo se posicionou no segundo lugar no número de pessoas que não acreditam no aquecimento global, com 16,3\% dos entrevistados. Tavares et al. (2010) constataram em estudo realizado com estudantes do ensino médio que, em Pederneiras e São Bernardo do Campo, entre discentes, também havia, na mesma ordem, entre essas quatro cidades, mais pessoas que não confiavam na veracidade das informações divulgadas.

\begin{tabular}{c|c|c|c|c|c|ccc}
\hline \multirow{2}{*}{ IDADES } & \multicolumn{2}{|c|}{ PEDERNEIRAS } & \multicolumn{2}{c|}{ S. B. DO CAMPO } & \multicolumn{2}{c}{ TAPIRATIBA } & \multicolumn{2}{c}{ S. A. DE POSSE } \\
\hline & $\mathrm{S}$ & $\mathrm{N}$ & $\mathrm{S}$ & $\mathrm{N}$ & $\mathrm{S}$ & $\mathrm{N}$ & $\mathrm{S}$ & $\mathrm{N}$ \\
\hline $20-29$ & 10 & 5 & 4 & 1 & 29 & 3 & 18 & 1 \\
\hline $30-39$ & 7 & 1 & 14 & 3 & 6 & 0 & 9 & 1 \\
\hline $40-49$ & 13 & 2 & 13 & 2 & 6 & 0 & 3 & 1 \\
\hline $50-59$ & 6 & 4 & 9 & 0 & 2 & 1 & 8 & 1 \\
\hline 60 e + & 1 & 0 & 1 & 2 & 2 & 1 & 5 & 0 \\
\hline TOTAIS & 37 & 12 & 41 & 8 & 45 & 5 & 43 & 4 \\
\hline
\end{tabular}

Tabela 6 - Pessoas que Acreditam no Aquecimento Global por Faixa Etária

Foi perguntado aos entrevistados que disseram acreditar no aquecimento da Terra se eles sabiam porque isso estava acontecendo: $12 \%$ deles não sabiam os motivos. Em Pederneiras todos os crédulos afirmaram conhecer as causas do fenômeno em questão. Em São Bernardo do Campo, no entanto, $22 \%$ daqueles que acreditavam, desconheciam as razões da elevação

Geografia Ensino \& Pesquisa, v. 15, n.2, p. 75-86, maio./ago. 2011

Aquecimento global e mudanças climáticas na visão de adultos residentes em cidades

paulistas das temperaturas. Eles totalizaram 14\% em Santo Antonio de Posse, e 11,1\% em Tapiratiba. Pessoas de todas as faixas etárias se manifestaram como desconhecedoras dos motivos que estão levando ao aquecimento do planeta, mesmo entre os mais jovens, que, em grande parte, estão cursando o curso superior. Entre as pessoas com idades de 20 a 29 anos elas abarcaram $11,5 \%$ daquelas que responderam a essa pergunta e entre os de 50 a 59 anos, $20 \%$ (tabela 7 ). 


\begin{tabular}{c|c|c|c|c|c|c|c|c}
\hline \multirow{2}{*}{ IDADES } & \multicolumn{2}{|c|}{ PEDERNEIRAS } & \multicolumn{2}{|c|}{ S. B. DO CAMPO } & \multicolumn{2}{c|}{ TAPIRATIBA } & \multicolumn{2}{c}{ S. A. DE POSSE } \\
\hline & $\mathrm{S}$ & $\mathrm{N}$ & $\mathrm{S}$ & $\mathrm{N}$ & $\mathrm{S}$ & $\mathrm{N}$ & $\mathrm{S}$ & $\mathrm{N}$ \\
\hline $20-29$ & 10 & 0 & 2 & 2 & 28 & 1 & 14 & 4 \\
\hline $30-39$ & 7 & 0 & 11 & 3 & 3 & 3 & 9 & 0 \\
\hline $40-49$ & 13 & 0 & 12 & 1 & 6 & 0 & 3 & 0 \\
\hline $50-59$ & 6 & 0 & 6 & 3 & 2 & 0 & 6 & 2 \\
\hline 60 e + & 1 & 0 & 1 & 0 & 1 & 1 & 5 & 0 \\
\hline TOTAIS & 37 & 0 & 32 & 9 & 40 & 5 & 37 & 6 \\
\hline
\end{tabular}

Tabela 7 - Pessoas que Sabem do Aquecimento Global e suas Causas por Faixa Etária

Também foi perguntado aos indivíduos que disseram acreditar no aquecimento global se eles sabiam das conseqüências que poderiam resultar do aumento das temperaturas. 14,5\% deles, de todas as faixas etárias, afirmaram desconhecer as conseqüências, valor ligeiramente maior do que os que disseram ignorar as causas. Da mesma forma que na pergunta anterior, em Pederneiras, todos os crentes disseram saber das ocorrências que poderiam advir do aumento térmico. Em São Bernardo do Campo, 31,7\% dos entrevistados desconheciam o que poderia resultar da elevação da temperatura do planeta, um percentual bem superior aos dos que não sabiam de suas origens. Esses dados condizem com os obtidos por Tavares et al. (2010), nesta cidade, entre estudantes do ensino médio (tabela 8).

\begin{tabular}{c|c|c|c|c|c|c|c|c}
\hline \multirow{2}{*}{ IDADES } & \multicolumn{2}{|c|}{ PEDERNEIRAS } & \multicolumn{2}{|c|}{ S. B. DO CAMPO } & \multicolumn{2}{c|}{ TAPIRATIBA } & \multicolumn{2}{c}{ S. A. DE POSSE } \\
\hline & $\mathrm{S}$ & $\mathrm{N}$ & $\mathrm{S}$ & $\mathrm{N}$ & $\mathrm{S}$ & $\mathrm{N}$ & $\mathrm{S}$ & $\mathrm{N}$ \\
\hline $20-29$ & 10 & 0 & 2 & 2 & 27 & 2 & 17 & 1 \\
\hline $30-39$ & 7 & 0 & 8 & 6 & 4 & 2 & 9 & 0 \\
\hline $40-49$ & 13 & 0 & 12 & 1 & 4 & 2 & 3 & 0 \\
\hline $50-59$ & 6 & 0 & 6 & 3 & 2 & 0 & 6 & 2 \\
\hline 60 e + & 1 & 0 & 0 & 1 & 0 & 2 & 5 & 0 \\
\hline TOTAIS & 37 & 0 & 28 & 13 & 37 & 8 & 40 & 3 \\
\hline
\end{tabular}

Tabela 8 - Pessoas que do Aquecimento Global e suas Conseqüências por Faixa Etária

A seguir foi pedido aos entrevistados que acreditavam no aquecimento global e disseram saber de suas conseqüências, uma relação de fatos que pudessem decorrer da elevação das temperaturas. Essa questão, também elaborada de forma aberta, permitiu que cada pessoa elencasse um ou mais eventos para demonstrar seu conhecimento sobre 0 assunto. 


\begin{tabular}{c|ccc|c|c|c}
\hline \multirow{2}{*}{ Conseqüências } & \multicolumn{7}{|c}{ Idades } \\
\hline & $20-29$ & $30-39$ & $40-49$ & $50-59$ & 60 e + & Totais \\
\hline Derretimento de Geleiras & 8,6 & & 3,4 & 3,1 & 1,3 & 21,9 \\
\hline Aumento do Nível do Mar & 5,8 & 5,5 & 2,4 & 1,6 & 1,0 & 16,8 \\
\hline Proliferação de Doenças & 1,3 & 6,0 & 1,0 & 1,0 & 0,5 & 5,5 \\
\hline Aumento deTempestades e Furacões & 3,4 & 1,7 & 1,6 & 0,5 & 0,3 & 6,8 \\
\hline Aumento de Secas & 3,7 & 1,0 & 3,4 & 2,1 & 0,5 & 14,2 \\
\hline Falta de Água & 4,5 & 4,5 & 3,4 & 2,1 & 1,0 & 14,4 \\
\hline Excesso de Calor & 7,1 & 3,4 & 3,9 & 3,4 & 0,8 & 19,1 \\
\hline Outras & 0,8 & 3,9 & 0,0 & 0,0 & 0,0 & 1,3 \\
\hline Total & 35,2 & 0,5 & 19,1 & 13,8 & 5,4 & 100,0 \\
\hline
\end{tabular}

Tabela 9 - Conseqüências Mencionadas do Aquecimento Global em \% por Faixa Etária

Os acontecimentos mais mencionados foram, em seqüência, o derretimento das geleiras $(21,9 \%)$, o excesso de calor $(19,1 \%)$, o aumento do nível do mar $(16,8 \%)$, a falta de água $(14,4 \%)$ e 0 aumento das secas $(14,2 \%)$. Os fenômenos mencionados pelos adultos foram os mesmos e na mesma ordem dos citados por adolescentes dessas cidades, conforme constatado por Tavares et al. (2010). Entre as pessoas que têm de 40 a 59 anos, o excesso de calor foi mais lembrado do que o derretimento das geleiras (tabela 9).

Perguntou-se às pessoas que confiavam no aquecimento global se elas adotavam medidas mitigadoras que pudessem contribuir para atenuar os resultados do evento, ao que $60,2 \%$ delas responderam afirmativamente, porém, os resultados oscilaram muito de uma cidade para outra. Assim, enquanto em Pederneiras 94,6\% disseram adotar alguma medida, em Santo Antonio de Posse elas eram praticadas por 46,5\%, em Tapiratiba por 48,9\%, e em São Bernardo do Campo, por $53,7 \%$ dos indivíduos. Destaque para a faixa etária de 40 a 49 anos, na qual $82,9 \%$ dos entrevistados executavam alguma ação com tal propósito (tabela 10).

Geografia Ensino \& Pesquisa, v. 15, n.2, p. 75-86, maio./ago. 2011

Aquecimento global e mudanças climáticas na visão de adultos residentes em cidades paulistas

\begin{tabular}{c|c|c|c|c|c|ccc}
\hline \multirow{2}{*}{ IDADES } & \multicolumn{2}{|c|}{ PEDERNEIRAS } & \multicolumn{2}{c|}{ S. B. DO CAMPO } & \multicolumn{2}{c}{ TAPIRATIBA } & \multicolumn{2}{c}{ S. A. DE POSSE } \\
\hline & $\mathrm{S}$ & $\mathrm{N}$ & $\mathrm{S}$ & $\mathrm{N}$ & $\mathrm{S}$ & $\mathrm{N}$ & $\mathrm{S}$ & $\mathrm{N}$ \\
\hline $20-29$ & 8 & 2 & 2 & 2 & 13 & 16 & 10 & 1 \\
\hline $30-39$ & 7 & 0 & 5 & 9 & 4 & 2 & 3 & 1 \\
\hline $40-49$ & 13 & 0 & 10 & 3 & 4 & 2 & 2 & 1 \\
\hline $50-59$ & 6 & 0 & 5 & 4 & 2 & 0 & 3 & 1 \\
\hline 60 e + & 1 & 0 & 0 & 1 & 0 & 2 & 2 & 0 \\
\hline TOTAIS & 35 & 2 & 22 & 19 & 23 & 22 & 20 & 4 \\
\hline
\end{tabular}

Tabela 10 - Pessoas que Adotam Ações Para Evitar o Aquecimento Global por Faixa Etária 


\begin{tabular}{c|c|c|c|c|c|c}
\hline Medidas & \multicolumn{7}{|c}{ Idades } \\
\hline & $20-29$ & $30-39$ & $40-49$ & $50-59$ & 60 e + & Totais \\
\hline Substituição de Lâmpadas & 6,3 & 4,5 & 6,3 & 3,4 & 0,6 & 21,1 \\
\hline Diminuição do Uso do Chuveiro & 4,5 & 4,5 & 7,4 & 5,7 & 1,7 & 23,8 \\
\hline Uso de Aquecimento Solar & 0,0 & 1,1 & 1,1 & 0,6 & 0,6 & 3,4 \\
\hline Diminuição do Uso do Carro & 4,5 & 1,7 & 2,7 & 1,7 & 0,6 & 11,2 \\
\hline Plantio de Árvores e Uso Cor Branca & 1,7 & 0,6 & 0,6 & 0,0 & 0,6 & 3,5 \\
\hline Reciclagem de Materiais & 10,2 & 5,7 & 10,2 & 6,3 & 1,7 & 34,1 \\
\hline Outras & 2,3 & 0,0 & 0,6 & 0,0 & 0,0 & 2,9 \\
\hline Total & 29,5 & 18,1 & 28,9 & 17,7 & 5,8 & 100,0 \\
\hline
\end{tabular}

Tabela 11 - Medidas Adotadas para Evitar o Aquecimento Global em \% por Faixa Etária

Foi solicitado, então, que os entrevistados mencionassem as medidas mitigadoras adotadas. Cada pessoa poderia citar, nestas circunstâncias, uma ou mais atitudes que julgassem contribuir para atenuar 0 aquecimento global. A ação mais mencionada foi a reciclagem de materiais, com $34,1 \%$ das menções, seguida pela diminuição do uso do chuveiro, com $23,8 \%$, substituição de lâmpadas, com $21,1 \%$ e a diminuição do uso do carro, com $11,2 \%$. Vê-se que 0 uso do transporte coletivo, da carona solidária ou o hábito de caminhar, que poderia ser freqüente nas cidades pequenas, não estão entre as medidas mais utilizadas. A reciclagem é algo instituído em várias cidades, com apoio das autoridades municipais e muitas vezes com a criação de cooperativas, visando reduzir os diversos tipos de resíduos sólidos depositados nos aterros sanitários e principalmente nos lixões, embora nem sempre a diminuição e/ou restrição relativas a estas áreas sejam verificadas de modo efetivo. Substituição de lâmpadas e diminuição no uso dos chuveiros representam importantes economias para o orçamento doméstico. As medidas mencionadas foram comuns às diversas faixas etárias (tabela 11).

\section{Conclusões}

As pessoas entrevistadas possuíam, na maioria, um nível de escolaridade considerado significativo, quando comparado às condições existentes no conjunto da população brasileira, pois $88 \%$ da amostra tinham, ao menos, o ensino médio completo. Também eram oriundas de cidades com características regionais geográficas, socioeconômicas e culturais bem distintas, decorrentes de multifuncionalidades paisagísticas diferenciadas, delineando marcada variação de cenários urbanos - de influências metropolitanas a rurais. São Bernardo do Campo, com mais de 800 mil habitantes, apresenta um PIB per capita elevado, uma economia baseada na indústria e no comércio, além de várias alternativas relacionadas às atividades culturais, quando considerado todo o dinamismo da área metropolitana de entorno do município. As outras três cidades são pequenas e, por essa razão, desprovidas de atividades culturais e de lazer diversificadas. Pederneiras, embora possua um comércio promissor, ainda tem seu desenvolvimento socioeconômico marcado pela dependência das atividades agropecuárias, verificando-se que Tapiratiba e Santo Antonio de Posse, também apresentam fortes ligações

Geografia Ensino \& Pesquisa, v. 15, n.2, p. 75-86, maio./ago. 2011

Tavares, A. C. et. all

ISSN 2236- 4994 
com o mundo rural e têm nas atividades agrícolas o esteio de suas economias, embora estejam próximos da região de influência da área metropolitana de Campinas. Assim, poder-se-ia esperar que pessoas residentes em lugares tão diversificados pudessem ter visões distintas concernentes a assuntos universais e polêmicos como o aquecimento global, demonstrando diferentes graus de preocupação e motivação para o desenvolvimento de condutas próambientais.

A quase totalidade das pessoas entrevistadas tinha ciência do aquecimento do planeta e, para $45,1 \%$ das pessoas, tal informação foi transmitida pela televisão. Outras $14,8 \%$ citaram a internet como fonte do conhecimento. Mesmo diante de um grupo de entrevistados com elevado nível de escolaridade, apenas $11,1 \%$ colheram subsídios sobre 0 aquecimento global nas escolas.

Entre os indivíduos que tinham conhecimento do aquecimento global, $14,9 \%$, a maior parte da cidade de Pederneiras, disseram não acreditar que esse processo estivesse em andamento. Foi também nesta cidade que todos os crédulos disseram saber a razão pela qual isso estava acontecendo e quais as conseqüências que poderiam resultar desse fato. Em São Bernardo do Campo, dos que acreditavam no aquecimento global, 22\% desconheciam as razões para isso, e $31,7 \%$ não sabiam os fenômenos que poderiam decorrer da elevação da temperatura.

O derretimento das geleiras $(21,9 \%)$, o excesso de calor $(19,1 \%)$, o aumento do nível do mar $(16,8 \%)$, a falta de água $(14,4 \%)$ e 0 aumento das secas $(14,2 \%)$ foram as principais conseqüências do aquecimento global mencionadas pelos entrevistados das quatro cidades. Tais fenômenos, com constância, aparecem nos noticiários e programas jornalísticos das emissoras de televisão, levando muitas vezes à apreensão de diversos posicionamentos ou até mesmo de informações equivocadas por meio de alguns canais de mídias, fundados em desinformação e/ou manipulação disseminadas por determinadas organizações ou instituições.

Na cidade de Pederneiras $94,6 \%$ dos entrevistados que confiam no aquecimento global disseram adotar alguma ação que 0 debilite. Em Santo Antonio de Posse tais medidas eram praticadas por 46,5\%, em Tapiratiba por 48,9\% e em São Bernardo do Campo por $53,7 \%$ dos indivíduos. Também nesse aspecto a cidade de Pederneiras apresentou uma feição diferenciada. A economia de energia, com a diminuição no uso do chuveiro e a substituição de lâmpadas, foi a medida mais citada pelos entrevistados, com $44,9 \%$, seguida pela contribuição para a reciclagem de materiais, que totalizou $34,1 \%$ das respostas. A economia de energia repercute diretamente na contenção das despesas familiares e é estimulada pelas autoridades e empresas distribuidoras em razão da alta demanda em relação à produção e à capacidade distributiva, enquanto a reciclagem de materiais é hábito instituído em numerosas cidades, por cooperativas estimuladas pelo poder público, com o intuito de introduzir mão de obra ociosa no mercado de trabalho e aliviar, principalmente lixões e aterros sanitários, de uma carga de lixo suplementar. Entretanto, estas medidas necessariamente podem não significar a adoção conscienciosa de um comportamento pró-ambiental efetivo, visto que implicam direta e indiretamente na economia doméstica. Outro ponto a ser questionado, é se realmente estes indivíduos praticam de fato ou se é outra pessoa na casa que é responsável pela implementação destas medidas nas residências.

Esses dados fazem pensar sobre o papel da televisão na difusão do conhecimento e dos padrões de comportamento relacionado à proteção ambiental da sociedade brasileira. $\mathrm{A}$ televisão mostra em suas imagens a diversidade de paisagens e os contrastes sociais e econômicos através de imagens cuidadosamente selecionadas e que envolvem mensagens 
subliminares que interferem na acuidade perceptiva tanto individual como coletiva, influenciando nos processos de valoração ambiental dos diferentes segmentos sociais existentes nas comunidades. Os avanços científicos e tecnológicos, as iniqüidades socioeconômicas - a riqueza, a pobreza e a exclusão social - se sucedem diante dos olhos dos telespectadores em quadros muitas vezes desconexos e fragmentados, levando a uma percepção também fragmentária, quando não marcada por distorções relativas a ser parte daquelas realidades ambientais (GUIMARÃES, 2007) . Todavia, a televisão preenche uma grande parte da vida social dos habitantes dos grandes centros urbanos e das pequenas cidades, transmitindo idéias, conceitos e valores, que, para um público fiel, disposto por várias horas diárias diante das telas, acabará induzindo, nem sempre de forma responsável, hábitos e direcionamentos referentes às atitudes cotidianas. Se sua influência é constatada entre as pessoas supostamente mais esclarecidas, entre aquelas com deficiente formação escolar, a televisão se torna a principal ou até mesmo a única fonte de informação. Neste sentido, o papel da televisão na formação de estudantes do ensino médio foi constatado por Tavares e al. (2010), ao estudar como eles encaravam a questão do aquecimento global.

Assim, para muitos, residentes em áreas urbanas ou rurais, em pequenas ou grandes cidades, ligados às atividades industriais, comerciais, agrícolas ou de prestação de serviços, 0 que é apresentado através das imagens televisivas, se torna verdade absoluta, concorrendo para que ela se torne, sob esse ponto de vista, ao difundir dados e fatos alarmistas e desprovidos de fundamentos científicos, também um veículo de desinformação, induzindo assim à apreensão de 'falsos rótulos' ambientais, que a médio e longo prazo resultarão em custos ambientais efetivos e potenciais para toda uma sociedade. 0 cidadão formado sob essa supremacia pouco contribuirá, por meio de uma sólida posição crítica e consciente, para a exigência, junto aos poderes constituídos, de ações e medidas legais coerentes e mais justas quanto ao estabelecimento de uma sociedade equilibrada e um ambiente estável.

A população de Pederneiras apresentou um comportamento diferenciado em relação aos habitantes das demais cidades, demonstrando não somente uma sensibilização e preocupação ambiental, como também um conseqüente desenvolvimento de ações pró-ambientais. Em Pederneiras mora a maior parte dos entrevistados que se mostraram céticos em relação ao aquecimento global, mas todos os crédulos lá residentes sabiam as causas e conseqüências de uma possível elevação das temperaturas do planeta. Entre esses, 94,6\% disseram adotar alguma ação com o objetivo de frear a ascensão térmica, em comparação com cerca da metade dos entrevistados nas outras localidades. Tais dados demonstram que, quando a maior parte do conhecimento da população provém da televisão e da internet, residir em locais economicamente mais desenvolvidos, com PIB mais elevado e maior possibilidade de acesso às diferentes formas e fontes do conhecimento, como é o caso de São Bernardo do Campo, não garante cidadãos mais críticos e esclarecidos quanto aos problemas e conflitos correlacionados ao meio ambiente e enfrentados na atualidade, nem mesmo níveis perceptivos mais complexos quanto às realidades vivenciadas, ou ainda a tomada de consciência expressa na adoção de comportamentos pró-ambientais (GUIMARÃES, 2007). Estes parecem ser os habitantes de Pederneiras, ao menos em relação ao assunto em pauta. 


\section{Referências}

INTERGOVERNMENTAL PANEL ON CLIMATE CHANGE - IPCC. Climate Change 2001: the scientific basis. HOUGTON J. T. et al. (eds.). Cambridge: Cambridge University Press, 2001.

INTERGOVERNMENTAL PANEL ON CLIMATE CHANGE - IPCC. Climate Change 2007: the physical science basis. SOLOMON, S. et al. (eds.). Cambridge: Cambridge University Press, 2007.

FUNDAÇÃO SISTEMA ESTADUAL DE ANÁLISE DE DADOS - SEADE. Informações Socioeconômicas. Disponivel em:<http://www.seade.gov.br/produtos/imp/index.php>. Acesso em 20 de abril de 2011.

GUIMARÃES, S.T.L. Paisagens: aprendizados mediante experiências. Um ensaio sobre interpretação e valoração da paisagem. 2007. Tese (Livre-docência) 2007. - Instituto de Geociências e Ciências Exatas, Universidade Estadual Paulista, Rio Claro/SP, 2007.

TAVARES, A. C. et al. Aquecimento global e mudanças climáticas na visão de estudantes do ensino médio. CLIMEP - Climatologia e Estudos da Paisagem, vol. 5, n. 1, p. 100-116, 2010. Disponível em:< http://www.periodicos.rc.biblioteca.unesp.br/index.php/climatologia/article/view/4180/3377>. Acesso em 20 de abril de 2011.

\section{Correspondência}

Antonio Carlos Tavares - Departamento de Geografia do Instituto de Geociências e Ciências Exatas da UNESP, campus de Rio Claro, SP. Avenida 24 A, 1515, CEP. 13506.900

E-mail: atavares@rc.unesp.br

Recebido em 30 de maio de 2010.

Aprovado em 30 de agosto de 2011. 